\title{
Hydrothermal Spallation Drilling Technology: An Alternative Method of Geothermal Energy Development
}

\author{
Mingbo Wang, Songyang Zhang and Gouemo Niangui Josue Edwin \\ School of Petroleum Engineering, China University of Petroleum (East China) Qingdao 266580
}

\begin{abstract}
Hydrothermal Spallation Drilling (HSD) is a relatively new method suitable for drilling through hard and brittle rocks usually encountered in deep wells and more commonly in geothermal well drilling. Up to $70 \%$ of the cost of a geothermal energy project is spent on drilling since today almost all deep wells are drilled by conventional rotary drilling. Among all sustainable energy sources geothermal energy has an advantage of its energy production being independent of climatic conditions, however to allow installation of geothermal power plants geothermal wells have to be drilled at low costs. Conventional rotary drilling in hard formation is expensive because of bit wear which causes more tripping during drilling and hence increases the cost. Therefore, HSD comes in to save the cost of drilling by up to $15-20 \%$. This document reviews the technology, its mechanism, status and future. With the global increment in the contribution of geothermal energy expected in the future, $5 \%$ of global energy by 2050, HSD is a game changing technology to increase the profitability and competitiveness of geothermal energy in relation with other sources of energy. However, just like any other technology HSD has shortfalls which are discussed in this document. These shortfalls have set a trend in the research world which has been mainly conducted in Switzerland and US. Overall assessment of the technology is promising and it will work to supplement conventional rotary drilling rather than replace it.
\end{abstract}

Keywords-hydrothermal spallation drilling; geothermal energy; drilling operation

\section{INTRODUCTION}

Geothermal energy is one of the sustainable energies available in the world today and is projected to contribute 5\% of the global energy by 2050. It is energy in the form of heat obtained from hot circulating ground water. For this energy to be obtained deep wells $(4-7 \mathrm{~km})$ have to be drilled, unlike oil and gas drilling, the rocks encountered in geothermal wells are more abrasive and hard. Oil and gas is found in rocks like limestones, shales and sandstones which are relatively easier to drill using the conventional rotary drilling, on the other hand, geothermal wells go through the hard metamorphic and igneous rocks like granites, taconites, quartzite and tight sandstones which make conventional rotary drilling less effective. The inefficiency is caused by the reduction in the rate of penetration (ROP) due to the hardness of the rock, this leads to a higher rate of bit wear and hence more trips and more money lost in the due process.

Though inefficient, conventional rotary drilling is still widely used in drilling geothermal wells worldwide, with it the cost of a geothermal project is increased, for it covers $70 \%$ of the cost as shown in figure 1. The following sections in this document summarize a new technology called Hydrothermal Spalling Drilling (HSD) that has been proposed to reduce the cost of drilling through hard rocks encountered in geothermal well drilling.

To get a better understanding of HSD we have to start from spallation, spallation or spalling process is the process that will fragment the rock into smaller parts through temperature gradients induced into rocks which can then be hydraulically transported to the surface. Spallation Drilling in deep wells is referred to as Hydrothermal Spallation Drilling because of the way the heat is generated downhole using water, air and fuel.

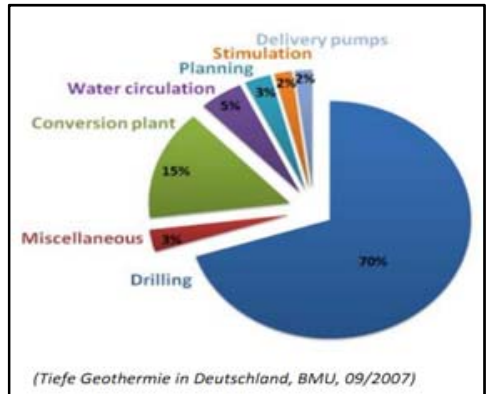

FIGURE I. COSTS OF A GEOTHERMAL POWER PLANT IN GERMANY

\section{MECHANISM OF HYDROTHERMAL SPALLATION DRILLING (HSD) TECHNOLOGY}

Today, all deep wells are literally drilled using conventional rotary drilling methods. A conventional rotary drilling rig which is a complex assembly of large heavy anchored to a mechanical structure whose basic function is to rotate a string of drill pipe and drill a hole in the ground, it must also pull the drill pipe out of the hole for drill bit changes and run the pipe back into the hole. This system works well in the soft, sedimentary rocks usually encountered when drilling oil and gas wells. In these softer rocks, rates of penetration reaching $30 \mathrm{~m} / \mathrm{hr}$ are typical. However, problems arise in harder, crystalline rocks such as taconite and granite, where instantaneous conventional drilling penetration rates are as low as $1-7 \mathrm{~m} / \mathrm{hr}$, with overall drilling speeds even lower due to the need for frequent bit replacement called tripping [1]. This also increases the cost of drilling wells.

A conceivable alternative to both drilling in hard rock and 
reducing drilling costs that increase exponentially with depth may be to use hydrothermal spallation drilling technology. HSD is the type of drilling which consists of heating the rock surface so quickly that thermal stresses induced in the rock cause it to fail forming spalls that are ejected from the surface [2]. Figure 2 shows a schematic diagram of the HSD.

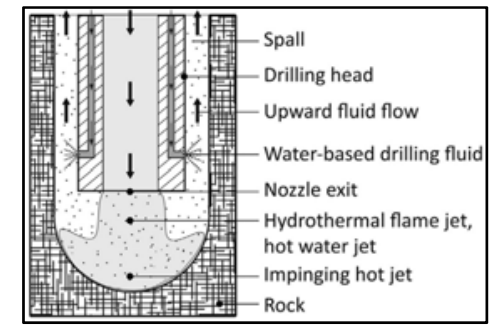

FIGURE II. SCHEMATIC DIAGRAM SHOWING A HYDROTHERMAL SPALLATION HEAD IN OPERATION[3]

HSD is characterized by the rapid heating of the confined rock surface. This rapid heating induces compressive thermal stresses caused by expansion of the solid with increasing temperatures lead to failure of the solid into small, disk-like flakes or spalls. These flakes or spalls are then ejected violently from the surface of the rock due to the stresses built up in the surface before fracture and carried back to the surface by the drilling fluids. Figure 3 summarizes this process.

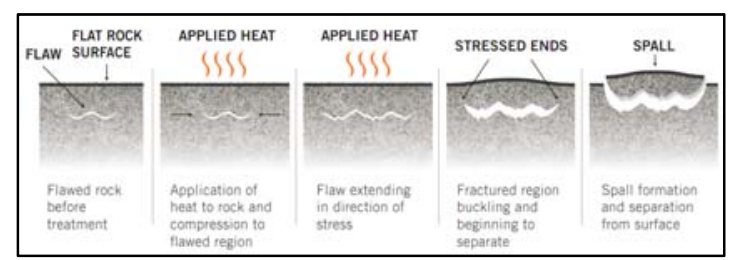

FIGURE III. HYDROTHERMAL SPALLATION DRILLING MECHANISM[4]

For the drilling of geothermal wells in hard, polycrystalline rock, usually, a water-based drilling fluid would be chosen. These drilling fluids consist of water and some functional additives, such as bentonite similar to those used in conventional rotary drilling of oil and gas. When you look at Figure 4 the major problem of transferring spallation drilling to deep boreholes filled with a water-based drilling fluid becomes readily obvious. The flame jet for spalling the rock has to be ignited and operated in the hostile aqueous environment of the drilling fluid being injected at some part of the drilling head. The same concern was also expressed in a report on advanced drilling systems published in 1996 by Pierce and co-workers: The authors of this report doubted, whether a flame jet for thermal spallation can be operated in this dense, aqueous environment and stated that the system "must (probably) operate in air". This problem of developing an underwater flame jet system, however, can nowadays be solved by socalled "hydrothermal flames".

The concept "hydrothermal combustion" was first introduced by Franck and his co-workers in 1993 to describe an oxidation process occurring in a dense aqueous environment at supercritical conditions. The vapor-liquid critical point of water is found at a temperature of $373.9^{\circ} \mathrm{C}$ and a pressure of
220.6 bar. Above this critical point liquid and gas phases are no longer distinguishable. Thus, if the temperature and pressure of a fluid are higher than the critical values, a fluid is considered to be "supercritical" state and is characterized by its homogeneity lacking any interfacial phase boundaries. Apart from the radical changes in the thermophysical properties of water near the critical point, water also undergoes a significant change in its polarity: In its supercritical state, water is a lot less polar than in its liquid state and hence becomes a good solvent for non-polar compounds such as oxygen, nitrogen or carbon dioxide. This absence of mass transfer limiting phase boundaries allows for combustion reactions between organic fuels (e.g. methane) and oxidizing agents (e.g. oxygen, air) in supercritical water. Thus, whereas liquid water is known to be a rather hostile environment for combustions reactions to take place, supercritical water is very suited to sustain a flame.

\section{A. Summary of HSD Mechanism}

Fuel, oxygen and water are individually injected into the reaction chamber from conduits. A specific device ignites the fuel and oxygen and a large amount of heat is generated. Water in the reaction chamber reaches the supercritical state $\left(\mathrm{Tc}=374.3^{\circ} \mathrm{C}, \mathrm{Pc}=22.1 \mathrm{MPa}\right.$ ) after the True Vertical Depth (TVD) exceeds a certain value with proper pump pressure. Fuel and oxygen are miscible in supercritical water, which accelerates the reaction.

The generated high temperature medium, mainly consisting of supercritical water and supercritical carbon dioxide, gushes out of the nozzle and impinges on the rock. The anisotropy of thermal conductivity of the rock causes non uniform thermal stresses which causes the rock to crack. With heat flux impinging on the rock and cuttings continuously being stripped from the rock surface, the well depth increases.

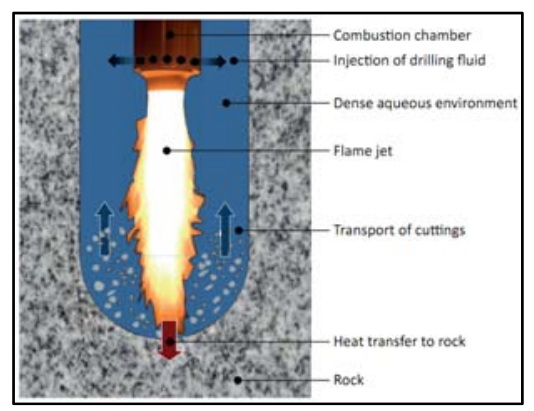

FIGURE IV. A SCHEMATIC DIAGRAM SHOWING THE DIFFERENT PARTS OF THE DOWNHOLE SYSTEM OF HSD

\section{HistORY AND STATUS OF HSD TECHNOLOGY}

HSD technology is one of the types of the broader group of Thermal drilling technology. Thermal drilling technology was invented in the middle of the 20th century and between the 1960's and 1980's research focused on flame jets working in an environment of ambient air and drilling shallow holes up to a maximum depth of $335 \mathrm{~m}$.

HSD technology was invented in the late 20th century (1995) by MIT researchers and Bob Potter. In 2004 Potter Drilling company was founded by Jared and Bob Potter to develop and commercialize the HSD technology. Potter drilling company has a pilot plant for HSD research in 
California. Another pilot plant for this research is in Switzerland at ETH Zurich, Institute of Process Engineering. The research done at both pilot plants has been mostly about Heat transfer mechanisms, supercritical behavior of fluids and technology optimization.

Recent studies have mainly focused on rock breaking by heat flux with relatively low nozzle outlet velocity, usually less than $20 \mathrm{~m} / \mathrm{s}[5,6]$ in a recent paper proposed a new design of a reaction chamber structure and adjusting injection parameters of HSD. In the paper focus was placed on jet velocity since distribution of velocity and pressure downhole have significant effects on rock breaking. A numerical model was made to investigate velocity and pressure distribution during HSD, the results were compared with those of a conventional water jet. These results provide a basis for better design of the reaction chamber in future.

Currently, most of the HSD research has been carried out mostly in Switzerland and US. With the increased search for an efficient and less costly way to drill geothermal wells HSD research is going to spread to more countries including China. The interest in this technology depends on the contribution of geothermal heat generation to a country's energy needs, figure 5 shows the Worldwide geothermal heat generation in 2010 .

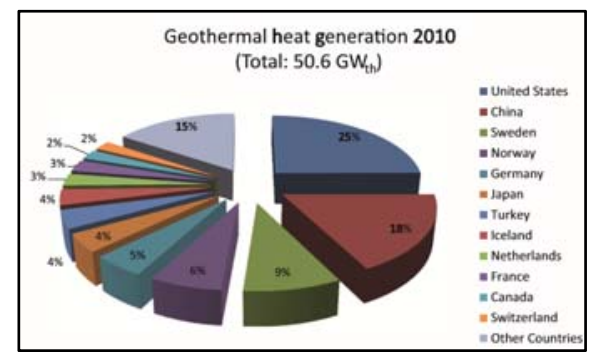

FIGURE V. WORLDWIDE GEOTHERMAL HEAT GENERATION IN 2010 [7]

\section{CONDITIONS OF HSD TECHNOLOGY}

HSD requires a minimum bottom hole pressure in order to be initiated and controlled. It requires high flux values but moderate surface temperature that doesn't exceed the brittleplastic transition temperature of the rock samples. For HSD to work in deep well drilling, a flame ignited in a high-density water-based drilling fluid at hydrostatic pressures exceeding the critical pressure of water (220.6 bar) should be used.

The degree of confinement of the heated rock area should be less than or equal to $10 \%$ of its total surface area. Higher than $10 \%$, the produced thermal stresses would be relived through the expansion of the rock which will not spall. Not all rocks are spallable, Table 1 show some examples of spallable and non-spallable. No single property of the rock determines whether or not a rock is spallable.

TABLE I. EXAMPLES OF ROCKS AND THEIR ABILITY TO SPALL

\begin{tabular}{|c|c|}
\hline Spallable (spall easily) & Non-spallable \\
\hline Granites & Limestones \\
\hline Taconites & Shales \\
\hline Quartzites & Basalts \\
\hline Tight sandstones & Soft sandstones \\
\hline
\end{tabular}

\section{AdVANTAgES OF HSD TECHNOLOGY}

Since most of the costs of a geothermal energy project are due to drilling costs, HSD technology is the right technology which can reduce the costs as explained in the following text.

During HSD, since there is no contact with the rock, the need for the drill bit wear and tripping time is reduced, hence reduction in drilling costs associated with bit replacements. This means there is a longer lifetime for a given bit which translates to less time lost in tripping during drilling. Drilling costs have been reported to reduce by $15-20 \%$ when using HSD technology.

HSD technology is a no-contact drilling approach hence no Weight On Bit(WOB) which improves the trajectory control.

There is a high Rate of Penetration (ROP) when using HSD in hard rocks compared to the conventional rotary drilling in the same, it has the potential to drill up to $10 \mathrm{~km}$ with limited performance degradation. Drilling tests in granite showed that Rate of Penetration (ROP) can reach $15 \mathrm{ft} / \mathrm{hr}-30 \mathrm{ft} / \mathrm{hr}$ (Potter et. al 2013) which is several times the ROP in conventional drilling. Penetration rates in crystalline, granitic rock using thermal spallation have been seen to be 5-10 times faster than those of conventional rotary drilling [8]. Table 2 shows laboratory measured rates of penetration.

TABLE II. FIELD TEST OF SPALLATION DRILLING AT AMBIENT CONDITIONS

\begin{tabular}{|c|c|c|c|l|c|}
\hline Rock & Depth & $\begin{array}{c}\text { Drilling } \\
\text { Rate }\end{array}$ & $\begin{array}{c}\text { Fuel- } \\
\text { oxidizer }\end{array}$ & $\begin{array}{c}\text { Chamber } \\
\text { pressure }\end{array}$ & $\begin{array}{c}\text { Air } \\
\text { flow }\end{array}$ \\
\hline $\begin{array}{c}\text { Granite, } \\
\text { Conway }\end{array}$ & $335 \mathrm{~m}$ & $15.8 \mathrm{~m} / \mathrm{hr}$ & $\begin{array}{c}\text { Fuel oil } \\
\text { and air }\end{array}$ & 34 bars & $\begin{array}{c}34.4 \\
\mathrm{~m}^{3} / \mathrm{min}\end{array}$ \\
\hline $\begin{array}{c}\text { Granite, } \\
\text { Barre }\end{array}$ & $130 \mathrm{~m}$ & $7.6 \mathrm{~m} / \mathrm{hr}$ & $\begin{array}{c}\text { Fuel oil } \\
\text { and air }\end{array}$ & 8.6 bars & $\begin{array}{c}34.4 \\
\mathrm{~m}^{3} / \mathrm{min}\end{array}$ \\
\hline $\begin{array}{c}\text { Granite, } \\
\text { Pedernal }\end{array}$ & $30 \mathrm{~m}$ & $6-7 \mathrm{~m} / \mathrm{hr}$ & $\begin{array}{c}\text { Fuel oil } \\
\text { and air }\end{array}$ & $7.6 \mathrm{bars}$ & $\begin{array}{c}31.5 \\
\mathrm{~m}^{3} / \mathrm{min}\end{array}$ \\
\hline
\end{tabular}

HSD technology makes geothermal well drilling and in turn geothermal electricity supply more profitable since it reduces the overall cost of the projects. This makes the geothermal energy production more competitive with other energy sources.

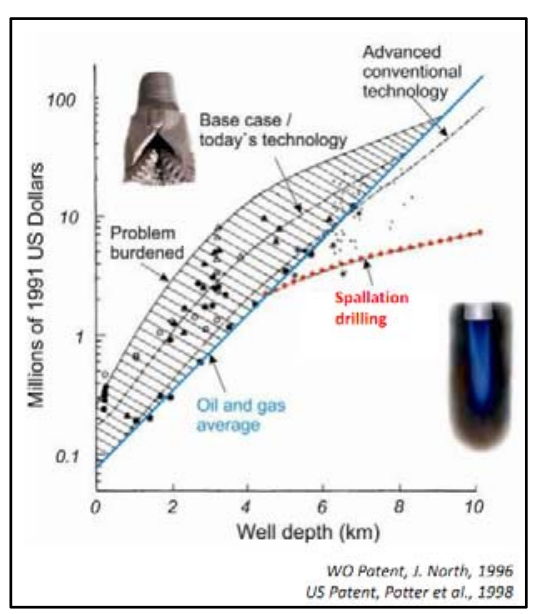

FIGURE VI. DRILLING COST INCREASES WITH DEPTH; A COMPARISION BETWEEN HSD AND CONVENTIONAL ROTARY DRILLING 
TABLE III. A QUICK SUMMARY OF THE DIFFERENCES BETWEEN CONVENTIONAL DRILLING AND HSD

\begin{tabular}{|c|c|}
\hline Rotary Drilling & HSD \\
\hline Good for soft rocks & Good for hard rocks \\
\hline ROP in soft rocks is $30 \mathrm{~m} / \mathrm{hr}$ & $\begin{array}{c}\text { ROP is 5-10 times faster than } \\
\text { conventional rotary drilling. }\end{array}$ \\
\hline Frequent need of bit replacements & Longer bit life \\
\hline Cost increases with depth rapidly & $\begin{array}{c}\text { Cost increases with depth but } \\
\text { less rapidly }\end{array}$ \\
\hline
\end{tabular}

\section{CHALLENGES OF Hydrothermal SPALlation DRILLING (HSD) TECHNOLOGY}

The main challenge of HSD technology is heat losses and overall efficiency of the technology. Entrainment of the relatively cool, aqueous, drilling fluid by the water jet leads to huge heat losses before the energy of the hot jet can be transferred to the rock. In a classic paper [8] found that penetration of supercritical jets to be equal to the injector's nozzle diameter and independent of the jet's temperature at the nozzle exit and the jet's mass flow under almost all experimental conditions.

Another challenge of HSD is the possible effect of hydrostatic pressure on jet performance and cuttings lift.

There is a possibility of limited thermal output from the initially selected heating system in HSD. Hence combustion in aqueous environment needs to be researched thoroughly. Hole gauge control is also a challenge.

The differences in the injection system of the in-situ fluid and the drilling fluids makes particle transport ineffective. Certain types of rocks cannot be spalled but just melt when heated, the melting of rocks requires higher temperature and the molten cuttings are difficult to transport, which limits the application of HSD. Figure 7 summarizes the challenges.

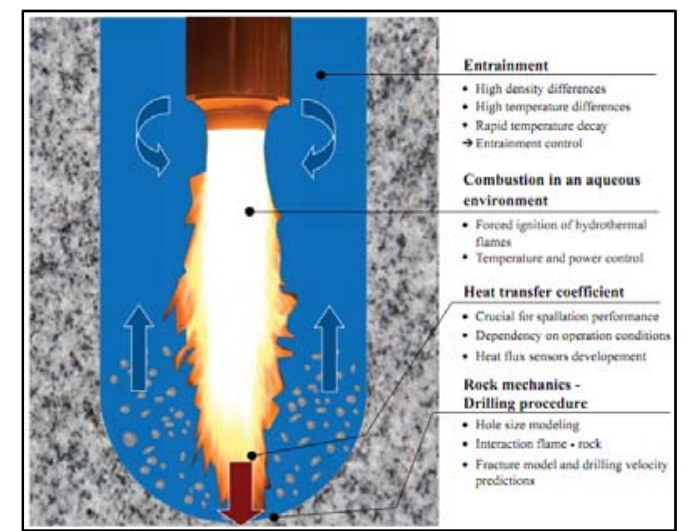

FIGURE VII. SUMMARY OF THE CHALLENGES OF HSD

\section{FUTURE OF HSD TECHNOLOGY}

HSD is expected to be adopted by the geothermal industry to curb the high costs of drilling wells. Future research should focus on the development of a sensor applicable in harsh downhole conditions, another thing to focus on is the development of an efficient spallation drilling bit. During the bit design focus should be put on nozzle designs. Heat losses being the main challenge of HSD should be well understood by doing further research.

\section{ACKNOWLEDGMENT}

This work was financially supported by "the Fundamental Research Funds for the Central Universities” with grant number 16CX05019A and the National Natural Science Foundation of China with grant number 51104171.

\section{REFERENCES}

[1] Armstead, H. C. H. and J. W. Tester (1987). Heat Mining. London, New York, E. \& F. N. Spon

[2] Chad R. Augustine (2009): Hydrothermal spallation and advanced energy conversion technologies for engineered geothermal systems, Phd Thesis - Iowa State University.

[3] Tobias Rothenfluh (2013): Heat Transfer phenomena of supercritical water jets in hydrothermal spallation drilling. Phd Thesis, ETH Zurich, Institute of Process Engineering.

[4] Rauenzahn, R. M. (1986). Analysis of Rock Mechanics and Gas Dynamics of Flame-Jet Thermal Spallation Drilling. Doctoral Thesis, Massachusetts Institute of Technology.

[5] Chad R. Augustine (2009): Hydrothermal spallation and advanced energy conversion technologies for engineered geothermal systems, Phd Thesis - Iowa State University.

[6] Xiaodong, Hu., Song, X., Li, G., Shen, Z., Cui, Peng, C. (2016, August 22): Numerical Analysis of Bottomhole Velocity and Pressure Distributions of High Pressure High Temperature Hydrothermal Jet. Society of Petroleum Engineers. doi:10.2118/180650-MS.

[7] J. W. Lund, D. H. Freeston, and T. L. Boyd. Direct utilization of geothermal energy 2010 worldwide review. In Proceedings World Geothermal Congress 2010. Bali, Indonesia, 2010.

[8] Tester, J. W., H. J. Herzog, Z. Chen, R. M. Potter and M. G. Frank (1994). "Prospects for Universal Geothermal Energy from Heat Mining." Science \& Global Security 5: 99-121. 